\title{
Research Canada calls for public investment in health research
}

\author{
— Cite as: CMAJ 2017 August 28;189:E1100. doi: 10.1503/cmaj.1095473
}

Posted on cmajnews.com on Aug. 4, 2017.

$\mathbf{F}$ undamental science research is the "primary fuel" of innovation, according to Research Canada, a national alliance dedicating to improving Canadian lives by championing health research. Investment in basic science, however, is woefully lacking in Canada, the group stated in a letter to House of Commons' Standing Committee on Finance.

As part of the consultations leading up to next year's federal budget, Research Canada is calling on the federal government to invest an additional \$485 million over four years in independent, investigator-led research. It is also asking for $\$ 300$ million annually for the Canadian Foundation for Innovation, created in 1997 to provide researchers with the tools they need to "contribute to the full spectrum of research." Other recommendations include additional financial support for young researchers, small capital grants and to "diversify opportunities for science-based graduate students."

The recommendations come from the final report of Canada's Fundamental Science Review, submitted to the government on April 10. Headed by Dr. David Naylor, a medical professor at the University of Toronto, the review's expert panel lamented Canada's eroding standing in research competitiveness compared to international peers. The report links this erosion to the decline of federal investment, relative to gross domestic product, in research and development over the past 15 years.

With respect to per capita investment in health research, specifically, Canada now ranks the lowest among industrialized nations, according to Research Canada, which suggests the country will only

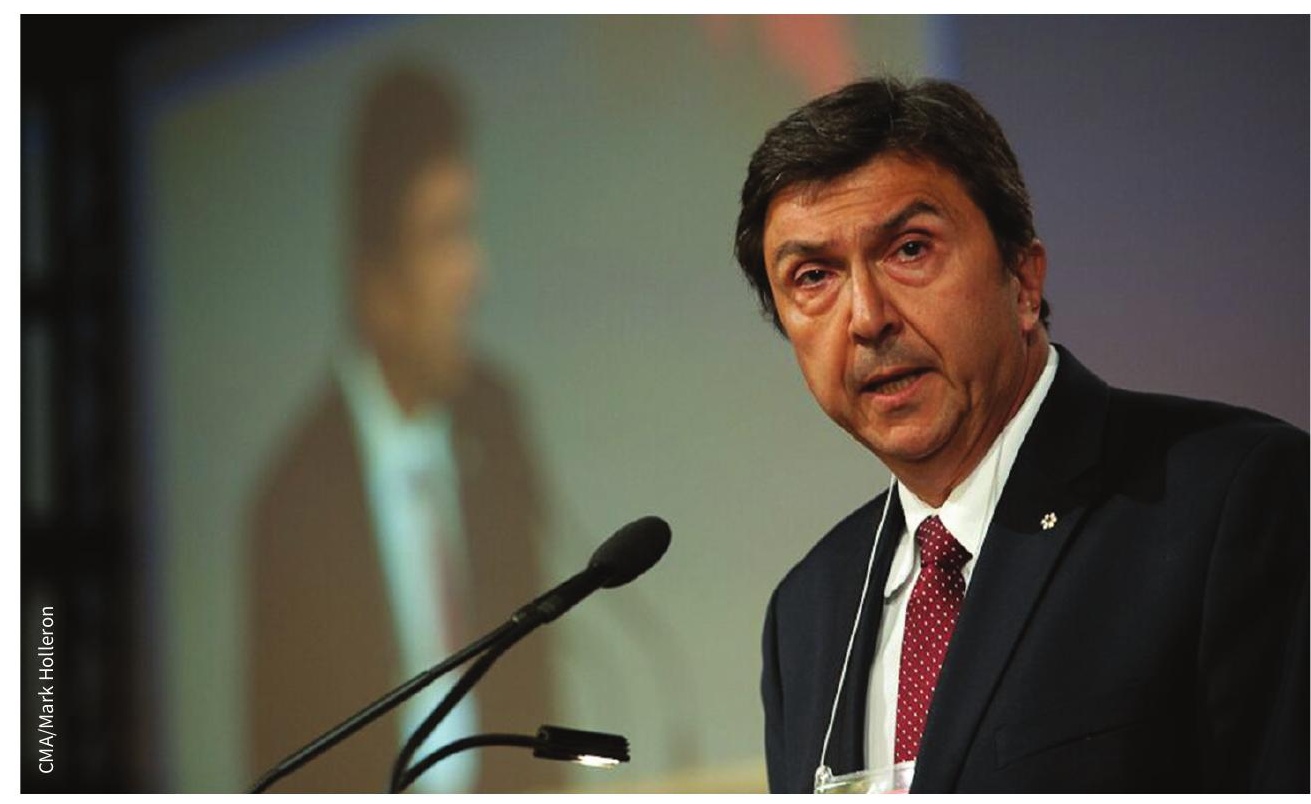

Research Canada calls on government to implement recommendations of expert panel led by Dr. David Naylor.

fall further behind as international peers dedicate more resources to research. As a result, the group noted in their submission to the standing committee, Canada is losing ground in "our share of published articles and total research output."

Investing more in fundamental research will benefit Canada in many ways, suggests Research Canada. It will ensure our most "promising minds" seek careers in Canada instead of looking elsewhere for work. The intellectual property generated through basic research will eventually lead to economy-boosting commercial opportunities, even if years down the road. Public funding of innovation also tends to draw more investment from private sources.

"Private enterprise cannot innovate and flourish in a vacuum," states the letter. "Sustained and renewed public investment in fundamental science is crucial to priming the starting piece of the innovation pipeline."

Research Canada also suggests that depending on research from other countries is inadequate for addressing the unique health needs of Canadians. Unique challenges include providing health care for one of the world's most multicultural populations, addressing the "disproportionate burden of disease and disability" in First Nations communities, and ensuring Canadians in remote locations have access to high-quality medical services.

"We need investment in made-inCanada health research that speaks to the particular needs and challenges of Canada's diverse population," states the letter.

Roger Collier, CMAJ 